\title{
THE EFFECT OF COOPERATIVE LANGUAGE LEARNING AND PERSONALITY TYPES TOWARDS ESSAY WRITING
}

\author{
Bejo Sutrisno \\ Foreign Language High School (STIBA) IEC Jakarta, Indonesia \\ E-mail: bjs_sutrisno@yahoo.co.id
}

Yumna Rasyid

Applied Linguistics, Postgraduate Program of Universitas Negeri Jakarta, Indonesia

E-mail: yumna.rasyid@unj.ac.id

Aceng Rahmat

Applied Linguistics, Postgraduate Program of Universitas Negeri Jakarta, Indonesia

E-mail: acengrahmat@gmail.com

\begin{abstract}
APA Citation: Sutrisno, B., Rasyid, Y., \& Rahmat, A. (2018). The effect of cooperative language learning and personality types towards essay writing. English Review: Journal of English Education, 6(2), 95-104. doi: 10.25134/erjee.v6i2.1259.
\end{abstract}

Received: 19-02-2018

Accepted: 29-04-2018

Published: 01-06-2018

Abstract: This study is aimed to find out the effect of Cooperative learning techniques and personality types on English essay writing skill. This study was conducted at STIBA - IEC Jakarta for the fourth semester in the academic year 2016/2017. It was an experimental study with the factorial design $2 \times 2$ at 0.05 significant level. The sample was 32 students and divided into two groups which each group was 16 students. The research reveals that: (1) students' English essay writing skill taught with Think-Pair-Share (TPS) technique was higher than with Student Team Achievement Division (STAD) technique; (2) English essay writing skill on introvert personality type was higher than extrovert personality types; (3) there was interaction effect between learning techniques and personality type toward English essay writing skill; and (4) students with introvert type taught with TPS technique was higher than those taught with STAD technique. There is an interaction effect between learning techniques and personality types on English essay writing skills.

Keywords: cooperative learning, essay writing skill, learning technique, personality type.

\section{INTRODUCTION}

An essay is definitely a set of paragraphs. An essay is composed of several long paragraphs with a topic as well as some paragraphs.

However, since the topic of the essay is too complex to be discussed in a paragraph, the author needs to divide it into several paragraphs, with one core discussion of each paragraph. Then the author needs to link the paragraphs by adding introductory sentences at the beginning of the paragraph and the sentence of conclusion at the end of the paragraph.

English essay writing skill is one of the language skills to be mastered by the fourth semester students after they got the lesson of how to write a paragraph, how to identify and create the topic sentence, how to identify and make the thesis statement in the first paragraph and how to arrange conclusion paragraph on a written English in previous semester. English essay writing skill is also an academic writing that needs to be mastered by every student to build their skill in writing scientific papers especially when the students have to do the final task in the form of thesis writing.

Two learning techniques are implemented in this research, they are learning techniques of Think-Pair-Share (TPS) and learning technique of Student TeamAchievement Divisions (STAD) for two groups of students that have the personality type of extrovert and introvert. Then, the 
results of the two groups are compared after the treatments of several meetings.

English writing is not a new subject for the students. They have started learning writing since they were in the first semester certainly with the different level of knowledge and skill in the set of process during the study with the different results. Basically, English essay writing has the objective to train students expressing their creative ideas in composition which cover the criteria of the essay writing such as format, mechanics, content, organization, grammar and sentence structure.

Techniques of Think-Pair-Share and Student Team-Achievement Divisions are two learning techniques of Cooperative Learning. In this cooperative learning model, students are expected to work together in one group or other group members so that they will be more motivated to improve their writing skills in English. Unfortunately, this cooperative learning model has not been widely applied by English lecturers in the classroom. The obstacles arose in learning with cooperative learning model is the students are accustomed to using the conventional learning patterns so it is not easy to form students' character to be able to apply cooperative learning model well and smoothly. It certainly takes time and process to familiarize the students of Semester IV especially in order to apply cooperative learning model well and smoothly.

With the cooperation in essay writing skills is expected to increase each member in each group. By working groups of each member will get the benefit from the exchange of ideas and knowledge among the members. What is already understood by a student is not necessarily understood by the other students and what is not understood by the student may have been understood by other students so that they can help each other.

Baradaran and Alavi (2015) stated that Cooperative writing is the instructional use of small groups so that students work together to maximize their own and each other's learning. In this way students will interact with each other and the teacher during the instructional session. There are various techniques found in cooperative learning. From a variety of techniques in cooperative learning, they have different strategies and ways of teaching but they have similarities in the learning objectives that involve team rewards, individual responsibility, and equal opportunities to get success. Meanwhile, according to Sonthara and Vanna (2009), teaching practices that provide opportunities to students to learn together in small groups are known as Cooperative Learning. Cooperative Learning is children learning together in groups, which are structured so that group members have to cooperate to succeed. Students work together to learn and are responsible for their team-mates' learning as well as their own. Astuti and Baratt (2018), in their research, stated their findings that Opportunities for student-student interactions in Cooperative Learning (CL) activities, absent in the conventional group work, may have contributed to the EFL learners' communicative competence. However, teachers new to CL should follow the preset procedures for CL strategies to promote individual accountability and understand how these activities benefit students. It is simply inferred that in CL, teacher should set and follow the procedures to conduct the teaching and learning activities using techniques of CL to make the activities run successfully.

Sharan (2015) breaks down some cooperative learning techniques, such as (1) Think-Pair-Share (TPS); (2) Student teamachievement divisions (STAD); (3) Team assisted individualization (TAI); (4) Jigsaw; and (5) Cooperative integrated reading and composition (CIRC). From the several learning techniques in cooperative learning mentioned above, basically they have the same concepts but different ways of teaching.

The writer applied two techniques for two different classes, they are all cooperative learning methods contribute to the idea that students who work together in learning and accountable to their teammates are able to make themselves learn equally well. Application of Think-Pair-Share (TPS) technique is a strategy which has been designed to let students think about the topic given to be formulated the ideas from every student, and then the ideas are distributed to 
ENGLISH REVIEW: Journal of English Education Volume 6, Issue 2, June 2018

the group members. When the teacher gives lessons to the class, the students sit in pairs with their teams. The teacher asks the class questions. Students are asked to think of an answer from themselves, then pair up with their partner to reach an agreement on the answer. Finally the teacher asks the students to share the answers they have agreed with the whole class.

On the other hand, according to Sharan (2015), in the TPS technique, the core group is divided into two pairs. The pairs are given a problem and they think about it. Thinking time is given to think (at least three to ten seconds). Students work in pairs and share their opinions. The pairs then share the answers to the whole students. This technique has three phases in application, namely (1) think; (2) pair; and (3) share. Think-Pair-Share technique which is part of cooperative learning besides giving opportunity to students to work alone and cooperate with other students also has other advantages that are student participation optimization, with classical method that allows only one student to go forward and share the result to the whole class.

Student Team Achievement Division (STAD) is a type of cooperative learning that emphasizes the existence of activities and interactions among students to mutually motivate and help each other in a learning task to get maximum results. Similarly, according to Sharan (2015) that Student Team Achievement Division (STAD) is a cooperative learning method which is the most studied by researchers. This method is also very adaptable that has been used in math, science, social sciences, English, engineering, and many other subjects, from the secondary school to college level. Based on the recent study conducted by Mahmoud (2014) related to his research finding that as for the attitude scale, the results obtained proved that the students developed positive attitudes towards using the cooperative learning approach to develop language skills in general and to develop their writing skills in particular.

Every individual has a distinctive personality that is not identical with others and cannot be replaced or substituted by others. There are characteristics or individual traits on
p-ISSN 2301-7554, e-ISSN 2541-3643 https://journal.uniku.ac.id/index.php/ERJEE

the psychical aspects that can differentiate themselves with others. Personality includes structures and processes that reflect innate traits and experiences. With regard to the various definitions of personality, there are some scholars who have formulated the personality based on the paradigm of the theory they have developed.

First, Sinha and Fatima (2013) stated that Extraversion-introversion dimension forms the core of human personality theories. It was Carl Jung who popularized the terms introversion and extraversion. Extraversion is the act, state, or habit of being predominantly concerned with and obtaining gratification from what is outside the self. While Introversion is the state of or tendency toward being wholly or predominantly concerned with and interested in one's own mental life.

Extraversion and introversion are part of a single continuum. Thus, a person who is high on extraversion is low on Introversion and vice versa.

Second, Qurrar-ul-Ain and Sadia Saeed (2017) stated that, "in the eyes of many language teachers, the personality of their students is a major factor contributing to success or failure in language learning. In order to determine how important, they rated personality and two other individual differences". And they added the statement that, "According to Carl Jung every individual has both personality traits introversion and extroversion but one trait is more prominent than the other. The terms are bit archaic as extraversion is not about being loud and introversion is not about being shy. It is about where people get their energy and motivation from, other people or themselves."

In relation to the personality types, Kayaoglu, in his journal titled Impact of Extroversion and Introversion on LanguageLearning Behaviors, gave his explanation of the extroverted and introverted types of learning that Although introverted and extroverted personality types have been identified in studies as significant factors in other areas of educational and psychological research, they have received only sporadic attention in studies of language learning 
strategies, which are very often associated with success in language learning.

By contrast, introverts are regarded as quiet and calm, with a tendency to be alone. According to Condon and Sahd (2013) that Introversion and shyness can affect students' social life on campus and influence strongly the ways in which students prefer to receive and process information in the classroom. There is no question that introversion confers valuable strengths: introverts tend to be better than extroverts at thinking before they act, taking in and processing information thoroughly, remaining on task, and working more accurately. Their non-combative nature and willingness to listen make them easy to get along with. While Zafar and Meenakshi (2012), through their research, conclude that while extroverts enjoy an advantageous position with regard to winning more opportunities for putting language into use, introversion is not thought to put learners in an inferior position, as this latter trait empowers learners to act better in terms of certain other skills including writing and reading. Yet, as risk-taking, which is a positive strategy in learning, is mostly associated with extroversion, extroverts in this study are regarded as more efficient learners in that they are said to be more actively involved in classroom process

In relation to the relevant research results that have been conducted by Mahmoed (2014), Akbar, Roohani, \& Hasanimanesh (2015), and Farrokhi, Nourelahi \& Elahi (2015). Mahmoed investigated about the effectiveness of using the cooperative language learning approach to enhance EFL writing skills among Saudi university students. Akbar, Roohani \& Hasanimanesh (2015), explored the impact of extroversion and introversion personality types on EFL learners' writing ability. The results of this study are students who have introvert personality type is significantly better in writing skills than students who have extrovert personality type; third, the research conducted by Farrokhi, Nourelahi, and Elahi (2015) with the title "Investigating the Relationship between Personality Type and Writing Performance of Iranian EFL Learners."
The results of this study are statistically indicated that there is a significant relationship between personality type and descriptive and argumentative writing skills, but the lack of a significant relationship between personality type and narrative writing skill and gender differences is not a significant factor in writing skills.

There were some previous researches about the extroversion and introversion towards the students' skill in writing and the difficulties of instruction to facilitate students in improving students essay writing. Most previous researchers tried to investigate the possible effect of extroversion/introversion personality traits on different features of EFL writing, such as content, organization, language, mechanics, and vocabulary. Here the writer investigates the students' essay writing skill on format, mechanics, contents, organization and grammar and sentence structure. The results of this study can help the lecturers to employ teaching strategies which fit different characteristics of extrovert and introvert learners.

In relation to the above explanation, the research questions and hypothesis posed in this study are as the following: (1) is there any statistically significant difference in English essay writing skill between groups of students taking classes with TPS learning techniques and group of students taking classes with STAD learning techniques?; (2) is there any statistically significant difference in English essay writing skills between groups of students with introverted and extroverted personality types?; (3) is there any statistically significant interaction effect between learning techniques and personality types on English essay writing skills?; and (4) For groups of students who have introverted personality types, is there any statistically significant difference in English essay writing skill between the students who take the lecture with the TPS learning techniques and the students who take the lecture with STAD learning techniques? Based on those research questions it can be understood that the objectives of the research are to find out if there are significant differences in English essay writing skill between groups of students taking classes with 
ENGLISH REVIEW: Journal of English Education Volume 6, Issue 2, June 2018

TPS and STAD learning techniques, to find out if there is statistically significant difference in English essay writing skills between groups of students with introverted and extroverted personality types, and to know if there is significant interaction effect between learning techniques and personality type.

\section{METHOD}

This study applied experimental research method which is a quantitative research using $2 \times 2$ factorial design which aims to determine the presence or absence of causal relationships between learning techniques and personality types towards students' skill in English essay writing skill. The participants of the study were 32 undergraduate foreign language school students of semester four majoring in English literature at STIBA-IEC Jakarta. They were divided into two groups of experiment class.

In order to homogenize the participants in terms of their language proficiency a free writing test was given. The participants were asked to write an essay of four paragraphs about 250 words on the topic "Do you prefer living in a big city or small town?" because the researchers thought it was a general topic which made it possible for almost all of the students to write about it. The second instrument used was about Personality Type test. This type of test asked students to answer some questions listed by choosing 'a' or ' $b$ '. Then the results were calculated and classified based on the criteria for being introvert or extrovert.

As explained previously, two sets of data were needed to conduct the present study: a composition test of essay writing performance and a questionnaire to determine personality type. The researcher explained to the participants that their responses would be used only for research purposes. Then each participant was given the instruments. It should be mentioned that all the participants were told not to write their names on the instruments, because it may affect their honesty in responding. Each data had a code, S1, S2, S3, S4, etc. For completing the personality type questionnaire, 75 minutes
p-ISSN 2301-7554, e-ISSN 2541-3643

https://journal.uniku.ac.id/index.php/ERJEE

were given to write an essay writing and 15 minutes were given for answering the personality type questionnaire. Among the participants who took the test, only sixteen students from each group, from the higher scores to the lower scores were selected as the sample for the study.

To deal with the data collection procedure, firstly, the Personality Type questionnaire was administered to be completed by the participants to decide the personality of each student. Secondly, they were asked to write an essay of four paragraphs on the presented topic within the time limit of one and half hour. The data collected were subjected to a two-way analysis of variance (two-way ANOVA) by the researcher, using SPSS (version 22) to answer the research questions.

\section{RESULTS AND DISCUSSION}

Based on the data analysis, the hypothesis testing, there were some findings. First, based on the measurement using Liliefors test, eight groups of the data came from the population that had normal distribution and based on Barlett test, all data groups have homogeny variance. Second, based on the Anova two lines measurement, it was known that there was significant difference between essay writing skill of students who were taught using TPS and students who were taught using STAD.

TPS learning technique from both personality types, introvert and extrovert, with $\mathrm{n}=16$, the lower score is 67 ; the higher score is 91; and the average score is 76.28; Second, STAD learning technique from both personality types, introvert and extrovert, with $\mathrm{n}=16$, the lower score is 62.7 ; the higher score is 83 ; and the average score is 72.4 ; Third, introverted personality type students with $\mathrm{n}=16$, the lower score is 65 ; the higher score is 91 ; and the average score is 76.8 ; Fourth, extroverted personality type students with $\mathrm{n}=16$, the lower score is 62.7 ; the higher score is 83 ; and the average score is 71.9 ; Fifth, group of introverted personality type students with TPS learning technique with $\mathrm{n}=$ 8 , the lower score is 74 ; the higher score is 91 ; 
and the average score is 82.1 ; and last, group of introverted personality type students with STAD learning technique with $\mathrm{n}=8$, the lower score is 65 ; the higher score is 80.3 ; and the average score is 71.5 .
The calculation of descriptive statistics for score data of the English essay writing skill can be seen in the following recapitulation table.

Table 1. Descriptive statistics of English essay writing skill score based on the calculation of SPSS 22

\begin{tabular}{|c|c|c|c|c|c|}
\hline & & $\overline{A_{1}}$ & $\overline{\mathrm{A}_{2}}$ & $\mathrm{~B}_{1}$ & $\mathrm{~B}_{2}$ \\
\hline \multirow[t]{2}{*}{$\mathrm{N}$} & Valid & 16 & 16 & 16 & 16 \\
\hline & Missing & 0 & 0 & 0 & 0 \\
\hline \multicolumn{2}{|c|}{ Mean } & 76.2750 & 72.4000 & 76.7563 & 71.9188 \\
\hline \multicolumn{2}{|c|}{ Std. Error of Mean } & 1.78294 & 1.38678 & 1.83196 & 1.21096 \\
\hline \multicolumn{2}{|c|}{ Median } & 74.0000 & 71.7000 & 76.5000 & 70.8500 \\
\hline \multicolumn{2}{|c|}{ Mode } & $69.00^{\mathrm{a}}$ & $70.00^{\mathrm{a}}$ & $72.70^{\mathrm{a}}$ & $69.00^{\mathrm{a}}$ \\
\hline \multicolumn{2}{|c|}{ Std. Deviation } & 7.13176 & 5.54713 & 7.32784 & 4.84386 \\
\hline \multicolumn{2}{|c|}{ Variance } & 50.862 & 30.771 & 53.697 & 23.463 \\
\hline \multicolumn{2}{|c|}{ Range } & 24.00 & 20.30 & 26.00 & 20.30 \\
\hline \multicolumn{2}{|c|}{ Minimum } & 67.00 & 62.70 & 65.00 & 62.70 \\
\hline \multicolumn{2}{|c|}{ Maximum } & 91.00 & 83.00 & 91.00 & 83.00 \\
\hline \multicolumn{2}{|c|}{ Sum } & 1220.40 & 1158.40 & 1228.10 & 1150.70 \\
\hline
\end{tabular}

a. Multiple modes exist. The smallest value is shown

\begin{tabular}{lrrrr}
\hline & $\mathrm{A}_{1} \mathrm{~B}_{1}$ & \multicolumn{1}{c}{$\mathrm{A}_{2} \mathrm{~B}_{1}$} & $\mathrm{~A}_{1} \mathrm{~B}_{2}$ & $\mathrm{~A}_{2} \mathrm{~B}_{2}$ \\
\hline $\mathrm{N} \quad$ Valid & 8 & 8 & 8 & 8 \\
\multicolumn{1}{c}{ Missing } & 0 & 0 & 0 & 0 \\
Mean & 82.0500 & 71.4625 & 70.5000 & 73.3375 \\
Std. Error of Mean & 1.87245 & 1.69421 & 1.76742 & 2.26289 \\
Median & 81.3500 & 71.5000 & 70.6500 & 72.8500 \\
Mode & 79.70 & 72.70 & 69.00 & 70.00 \\
Std. Deviation & 5.29609 & 4.79194 & 2.17058 & 6.40043 \\
Variance & 28.049 & 22.963 & 4.711 & 40.966 \\
Range & 17.00 & 15.30 & 7.00 & 20.30 \\
Minimum & 74.00 & 65.00 & 67.00 & 62.70 \\
Maximum & 91.00 & 80.30 & 74.00 & 83.00 \\
Sum & 656.40 & 571.70 & 564.00 & 586.70 \\
\hline
\end{tabular}

Before conducting the research hypothesis testing, the writer tested the requirements of the normality test and homogeneity test to determine whether the data is normal or homogeneous.

The normality test is conducted to find out whether the sample used in this study is from a normally distributed population or not.
There were 32 respondents in this study with the sample consisting of 16 respondents of introverted personality type and 16 respondents of extroverted personality type which were divided into two classes of research using Think-Pair-Share (TPS) technique and Student Team Achievement Division (STAD) technique.

Table 2. The summary of normality test result recapitulation

\begin{tabular}{|c|c|c|c|c|}
\hline Group & $\begin{array}{c}\text { Number of } \\
\text { sample }\end{array}$ & $\mathbf{L}_{\text {value }}$ & $\mathbf{L}_{\text {tabel }}$ & Results \\
\hline TPS (A1) & 16 & 0.188 & 0.213 & Normal distribution \\
\hline STAD $\left(\mathbf{A}_{2}\right)$ & 16 & 0.120 & 0.213 & Normal distribution \\
\hline Introvert $\left(\mathbf{B}_{1}\right)$ & 16 & 0.110 & 0.213 & Normal distribution \\
\hline Extrovert $\left(\mathbf{B}_{2}\right)$ & 16 & 0.181 & 0.213 & Normal distribution \\
\hline TPS and Introvert $\left(A_{1} B_{1}\right)$ & 8 & 0.171 & 0.285 & Normal distribution \\
\hline STAD and Introvert $\left(A_{2} B_{1}\right)$ & 8 & 0.148 & 0.285 & Normal distribution \\
\hline TPS and Extrovert $\left(A_{1} B_{2}\right)$ & 8 & 0.130 & 0.285 & Normal distribution \\
\hline
\end{tabular}




\begin{tabular}{lllll}
\hline STAD and Extrovert $\left(\mathbf{A}_{2} \mathbf{B}_{2}\right)$ & 8 & 0.160 & 0.285 & Normal distribution \\
\hline
\end{tabular}

The next requirement test is homogeneity test to determine whether the population variance is homogeneous or not.
Homogeneity test is done for group with the treatment (A) and attributed group (B) using F-test.

Table 3. Homogeneity test variance between group TPS $\left(A_{1}\right)$ and STAD $\left(A_{2}\right)$

\begin{tabular}{ccccc}
\hline Group & Db & $\mathbf{s}^{\mathbf{2}}$ & $\operatorname{Log~s}^{\mathbf{2}}$ & $\mathbf{d k} \log \mathbf{~ s}^{\mathbf{2}}$ \\
\hline TPS & 15 & 50,86 & 1,71 & 25,60 \\
STAD & 15 & $\mathbf{3 0 , 7 7}$ & 1,49 & 22,32 \\
Total & 30 & & & $\mathbf{4 7 , 9 2}$ \\
\hline
\end{tabular}

Based on the calculation of Barlett test gained $\mathrm{X}_{\text {value }}^{2}=1.65$, compared with $\mathrm{X}^{2}$ table for $\alpha=0,05$ and $d b=1$ is gained $X_{(0,05)(1)}^{2}=2.41$. the result showed that $X^{2}$ value $<X^{2}$ table. In indicated that $\mathrm{H}_{\mathrm{o}}$ is accepted. Thus, essay English writing skill from the two groups are derived from homogeneous sample.

Homogeny Test of variance between group Introvert $\left(\mathrm{B}_{1}\right)$ and Extrovert $\left(\mathrm{B}_{2}\right)$ is done using Barlett test with the significance level $\alpha=0.05$. the hypothesis testing are:

$$
\begin{array}{ll}
\text { Ho : } & \sigma^{2} \mathrm{~B}_{1}=\sigma^{2} \mathrm{~B}_{2} \\
\text { H1 : } & \operatorname{not~} \mathrm{H}_{\mathrm{o}}
\end{array}
$$

The criterion of rejection and acceptance of $\mathrm{H}_{\mathrm{o}}$ is if $\mathrm{X}^{2}$ vlue $>\mathrm{X}^{2}$ table, $\mathrm{H}_{\mathrm{o}}$ is rejected and if $\mathrm{X}^{2}$ value $\leq \mathrm{X}^{2}$ table, Ho is accepted.

The calculation of both groups testing at the significance level $\alpha=0.05$ is presented in the following table.

\begin{tabular}{|c|c|c|c|c|}
\hline Sample Group & Db & $\mathrm{s}^{2}$ & $\log s^{2}$ & $d k \log s^{2}$ \\
\hline Introvert & 15 & 53.70 & 1.73 & 25.95 \\
\hline Extrovert & 15 & 23.46 & 1.37 & 20.56 \\
\hline Total & 30 & & & 46.51 \\
\hline
\end{tabular}

Table 4. Homogeneity test of variance between group introvert $\left(B_{1}\right)$ and Extrovert $\left(B_{2}\right)$

Based on the calculation of Barlett test gained $X^{2}$ hit $=2.29$ compared with $X^{2}$ table for $\alpha=0.05$ and $d b=1$ gained $X_{(0,05)(1)}^{2}=2.41$. the result showed that $\mathrm{X}^{2}$ value $<\mathrm{X}^{2}$ table. It means that $\mathrm{H}_{\mathrm{o}}$ is accepted. Thus, essay English writing skill from the two groups are derived from homogeneous sample.

From the data analysis above, the hypothesis testing, there were some findings. First, based on the measurement using Liliefors test and based on Barlett test, all data groups has homogeny variance. Second, based on the Anava two lines measurement, it was known that there was significant differentiate between essay writing skill of students who were taught using Think-Pair-Share (TPS) and students who were taught using Students Team Achievement Division (STAD) (F value $>$ F table $=4.20)$. Besides, there was an interaction of learning techniques and personality type $($ Fvalue $=14.19>$ Ftable $=4.20)$. So that, the result of analysis result and hypothesis testing fulfill the criteria, and the next activity was hypothesis test using Tukey Test to know the strength of the fourth hypothesis. The following are the answers of the four research questions which have been stated previously.

Apparently, the first hypothesis was significant after the analysis using Anava test. The average score of essay writing skill of students who were taught using TPS (76.28) was higher than students who were taught using STAD (72.4). Fvalue $(=4.970)>$ Ftable $(=4.20)$. So that, it can be concluded that essay writing skill of students who were taught using TPS technique was higher than students who were taught using STAD technique. Theoretically, groups of students treated with TPS technique gained a more active, creative, and persuasive learning experience with members in their respective groups. This is evidenced by the mutual input, especially by some students who feel having higher level of understanding of certain components in essay English writing than other members during the learning process. TPS learning technique 
provides many benefits in the learning process such as the creation of interaction between members in the group and the interaction between groups in one class.

The second hypothesis was significant after the analysis using Annova test. The average score of essay writing skill of students who have introvert personality type (76.76) was higher than students who have extrovert personality type (71.92). $F_{\text {value }}(=\mathbf{7 . 7 4 5})>$ Ftable $(=4.20)$. So that, it can be concluded that essay writing skill of students who have introvert personality type was higher than students who have extrovert personality type. Groups of students with extroverted personality types have higher sociability and more interaction than students with introverted personality types who are more intent to the territorial nature and prefer concentration rather than interaction. It is what has been described in previous theories about the difference between extroverted and introverted personality types where extrovert personality type is more on the condition of sociability, interaction and multiplicity of relationship while introverted personality type is more in concentration condition, has depth in thinking to pour his ideas and interests on internal reactions. Although students with introverted personality types have more concentration than interaction, they were able to run cooperative learning well in discussion and gave each other explanation and understanding to members in group.

The third hypothesis was significant. It was showed by the result of Anava testing, which Fvalue $=14.190>$ Ftable $(0.05)=4.20$. So that, it can be concluded that there was interaction between the use of learning technique with personality type toward essay writing skill of students. It can be inferred that learning techniques will affect student learning outcomes if the selection of learning techniques in accordance with learning objectives and student characteristics. To achieve the learning objectives, lecturers must be able to apply various appropriate teaching techniques in accordance with the characteristics of students. In addition, to achieve the learning objectives, the lecturers must also master the models and teaching strategies and they should be able to master a variety of teaching techniques.

The summary of the results of each hypothesis can be seen in the table below.

Table 5. Summary of two-way variance analysis test

\begin{tabular}{lccc}
\hline Hypothesis & Fvalue & $\begin{array}{c}\text { Ftable } \\
(\mathbf{a}=\mathbf{0 . 0 5})\end{array}$ & Conclusion \\
\hline First & & 4.20 & Significant \\
Second & 4.970 & 4.20 & Significant \\
Third & 7.745 & 4.20 & Significant \\
\hline
\end{tabular}

The fourth hypothesis was significant after being analyzed using Tukey test. The average score of essay writing for introverted students who were taught using TPS and STAD with the Qvalue (6.091) was higher than Qtable $(0.05: 4: 8)=4.53$. It can be concluded that essay writing skill of introvert students who were taught using TPS was higher than taught using STAD technique. Thus it can be concluded that on the score of the result of the English essay writing skill test students who have introverted personality type who were given the TPS learning technique is higher than the group of students who were given STAD learning technique. In this case the group of introverted personality type students who were given the technique of TPS learning got better learning outcomes and increased from the group of students who were given STAD learning technique. By referring to the average score of extroverted students with the TPS learning technique $(\bar{Y}=82.05)$ is better than those who were given the treatment with the STAD technique $(\overline{\mathrm{Y}}=71,46)$ towards English essay writing skill. 
Table 6. The Result of Tukey Test

\begin{tabular}{lccc}
\hline Hypothesis & Qvalue & $\begin{array}{c}\text { Qtable } \\
(\mathbf{a}=\mathbf{0 . 0 5})\end{array}$ & Conclusion \\
\hline Fourth & 6.091 & 4.53 & Significant \\
\hline
\end{tabular}

\section{CONCLUSION}

At this conclusion some results of data analysis which have been presented in the above analysis result are explained. First, English essay writing skill in groups of students who attend lectures with TPS learning techniques is higher than the group of students who attend the lectures with STAD learning techniques. Second, English essay writing skill in groups of students with introverted personality types is higher than that of students with extroverted personality types. Third, there is an interaction effect between learning techniques and personality types on English essay writing skills. This shows that there is a very significant interaction effect between learning techniques and personality types on English essay writing skills. Fourth, the English essay writing skill of the group of introverted personality type students who attended the lectures with the TPS learning technique is higher than those who attended the lectures with the STAD learning technique.

It can be concluded that the application of learning technique of English essay writing skill which is based on the students' personality type can influence to the improvement of English essay writing skill. The group of introverted students who follow the lectures with the TPS learning techniques can affect to the English essay writing skill. Similarly, in groups of extroverted students who have lectures with STAD learning techniques can affect the skills of writing an English essay. So it can be concluded that both learning techniques and personality types affect the students' skills in English essay writing.

\section{REFERENCES}

Ain, Q. U., \& Saeed, S. (2017). Relationship of personality traits and writing skills among EFL learners at post-graduation level. Asian Innovative
Journal of Social Sciences and Humanities, 1(1), 12-25.

Akbar, J. B. A, Roohani, A., \& Hasanimanesh, A. (2015) The impact of extroversion and introversion personality types on EFL learners' writing ability. Journal of Theory and Practice in Language Studies, 5 (1), 212-218.

Astuti, P., \& Barratt, L. (2018). Individual accountability in cooperative learning in EFL classrooms more opportunities for peer interaction. The Journal of Asia TEFL, 15(1), 116.

Baradaran, A., \& Alavi, Reza, M. (2015). The differences between extrovert/introvert EFL learners cooperative writing. International Journal of Language and Applied Linguistics World (IJLLALW), 8(2), 13-24.

Condon, M., \& Sahd, R. L. (2013). Responding to introverted and shy students: Best practice guidelines for educators and advisors. Open Journal of Nursing 3(1), 503-515.

Farrokhi, Nourelahi, G., \& Elahi, M. H. N. (2015). Investigating the relationship between personality type and writing performance of Iranian EFL learners. Journal of Literature, Language and Linguistics, 13(1), 35-46.

Kayaoglu, M. N. (2013). Impact of extroversion and introversion on language-learning behaviours. Social Behavior and Personality Journal, 4(5), 819-826, DOI: 10.2224/sbp.2013.41.5.819.

Mahmoed, M. W. (2014). The effectiveness of using the cooperative language learning approach to enhance EFL writing skills among Saudi university students. Journal of Language Teaching and Research, 5(3), 616-625.

Oshima, A., \& Hogue, A. (2006). Writing academic English. New York: Pearson Education Inc.

Sharan, S. (2015). Handbook of cooperative learning method. Kirjastaja: Marston Book DMARSTO Orphans.

Sonthara, K., \& Vanna, S. (2009). Cooperative learning: Theory \& practice. Cambodia: USAID.

Sinha, A., \& Fatima, S. (2013). Impact of extrovertintrovert personality on individually's level of creativity: An emperical study. Indian Journal Applied Research 3(12), 524-526.

Zafar, S., \& Meenakshi, K. (2012). A study on the relationship between extroversion-introversion and risk-taking in the context of second language acquisition. International Journal of Research Studies in Language Learning, 1(1), 33-40. 
Bejo Sutrisno, Yumna Rasyid, \& Aceng Rahmat

The effect of cooperative language learning and personality types towards essay writing 